\title{
Formula One and global road safety: response by the FIA Foundation
}

\author{
David Ward
}

$J$ R Soc Med 2007; 100:412-413

The claim by Professor Ian Roberts ${ }^{1}$ in the August edition of $J R S M$ that the FIA Foundation is party to 'corporate capture' of road safety by the automobile industry is false (JRSM 2007;100:360-362). The FIA Foundation has no relationship with industry whatsoever and plays a leading role in promoting higher automobile safety standards worldwide, for example through independent consumer crash test programmes.

Professor Roberts' article states that road safety education is our favourite policy, but this is also false. We strongly support the 'safety systems' approach to road traffic injury prevention based on the work of the leading road safety epidemiologist William Haddon. Education and awareness campaigns have a role to play but only in conjunction with vehicle and road engineering and police enforcement.

Professor Roberts claims that the Federation International de l'Automobile (FIA) set up the Commission for Global Road Safety (CGRS), but this is again false. The FIA is the non-profit association of motoring clubs and helped to create the FIA Foundation through a $\$ 300$ million donation in 2001. However, the FIA Foundation is an independent UK-registered charity and it is we who established the CGRS, not the FIA.

The CGRS is promoting road safety as an important issue of sustainable development and calling for a $\$ 300$ million action plan to support the implementation of the World Bank/WHO 2004 World Report on Road Traffic Injury Prevention, which we agree is the primary source of well-designed road safety policies. The Commission is also calling for a first ever global UN Ministerial Conference on road safety.

Professor Roberts is opposed to investment in road infrastructure. However, the Millennium Project led by Professor Jeffrey Sachs, the 2005 Africa Commission Report and the Development Assistance Committee of the OECD all show that improved transport infrastructure, including roads, will contribute to the Millennium Development Goals. This was recognized by the G8 leaders

Director General, FIA Foundation, 60 Trafalgar Square, London WC2N 5DS, UK Website: www.fiafoundation.com

Email: d.ward@fiafoundation.com at the Gleneagles Summit in 2005 and aid for roads is increasing. The key question, however, is whether new roads in Africa will increase exposure of children and pedestrians to traffic moving at higher speeds. We fervently hope not, and that is why the CGRS is campaigning for safer road design to better protect vulnerable road users.

The CGRS has twelve members, from the G8 countries, Costa Rica, Kenya, India and Oman. They include a leading economist, a medical Professor, a Minister of Transport, a Head of Road Traffic Police, a UN diplomat, a public health specialist, a road safety NGO, a tyre company executive and just one representative from a motor vehicle manufacturer. Three members do have links to automobile clubs. Professor Roberts highlights Prince Michael of Kent's interest in motor sport but fails to mention his role promoting the Prince Michael Road Safety Awards. The Commission was supported by an Editorial Advisory Board which included road safety experts from the WHO, the World Bank and the Organisation for Economic Cooperation and Development (OECD).

Professor Roberts' most outrageous suggestion is that the FIA Foundation does 'not intend to fund road safety efforts themselves but will dictate how other organizations spend their money'. This is again entirely false. We have funded a wide range of safety activities, including the World Bank Global Road Safety Facility, the WHO's Prevention Strategy and World Report, the 2004 World Health Day, the UN Road Safety Collaboration and the 2007 UN Global Road Safety Week. We have not sought to direct these organizations or events in any way that is against the interests of vulnerable road users or in support of corporate interests. It is also rather surprising that Professor Roberts is so confused about our role, as he was sufficiently informed to apply to us for grant funding last year.

Professor Roberts makes much of Formula One's role in alleged 'corporate capture'. In fact the FIA's donation to the Foundation came from the sale of its interest in the television rights to Formula One. So the sport gave a remarkable charitable donation which the Foundation is now using to promote road safety and the environment. In fact, Formula One has a remarkable record of injury prevention, achieved in a way which Professor Roberts should applaud, by relying on vehicle and track safety systems rather than driver behaviour. It has also enabled 
global celebrities like Michael Schumacher to highlight the appalling public health crisis occurring on the world's roads.

We fully agree with Professor Roberts that air quality and climate change are vital issues. For that reason, the Foundation is a partner in the UN Environment Programme campaign to abolish the use of leaded fuels and promoting low sulphur fuels instead. These will enable the introduction of advanced emission reduction systems which are urgently needed, especially in rapidly motorizing nations. We also run the 'Ecotest' programme, which independently tests the emissions of both pollutants and carbon dioxide from new cars.

Today there are 600 million motor vehicles on the planet. This number is forecast to double by 2020 . We can debate whether such an increase is sustainable or how to prevent it: however, I suspect that telling Africans, Chinese and Indians that they should not have similar transport choices to our own will be not be effective. The FIA Foundation's response to this challenge is to try to help ensure that growing levels of motorization are much safer and more environmentally sustainable than before. This is our own agenda and not one determined by any corporate interests.

Competing interests DW is the Director General of the FIA Foundation.

\section{REFERENCE}

1 Roberts I. Formula One and global road safety. J R Soc Med 2007; 100:360-2

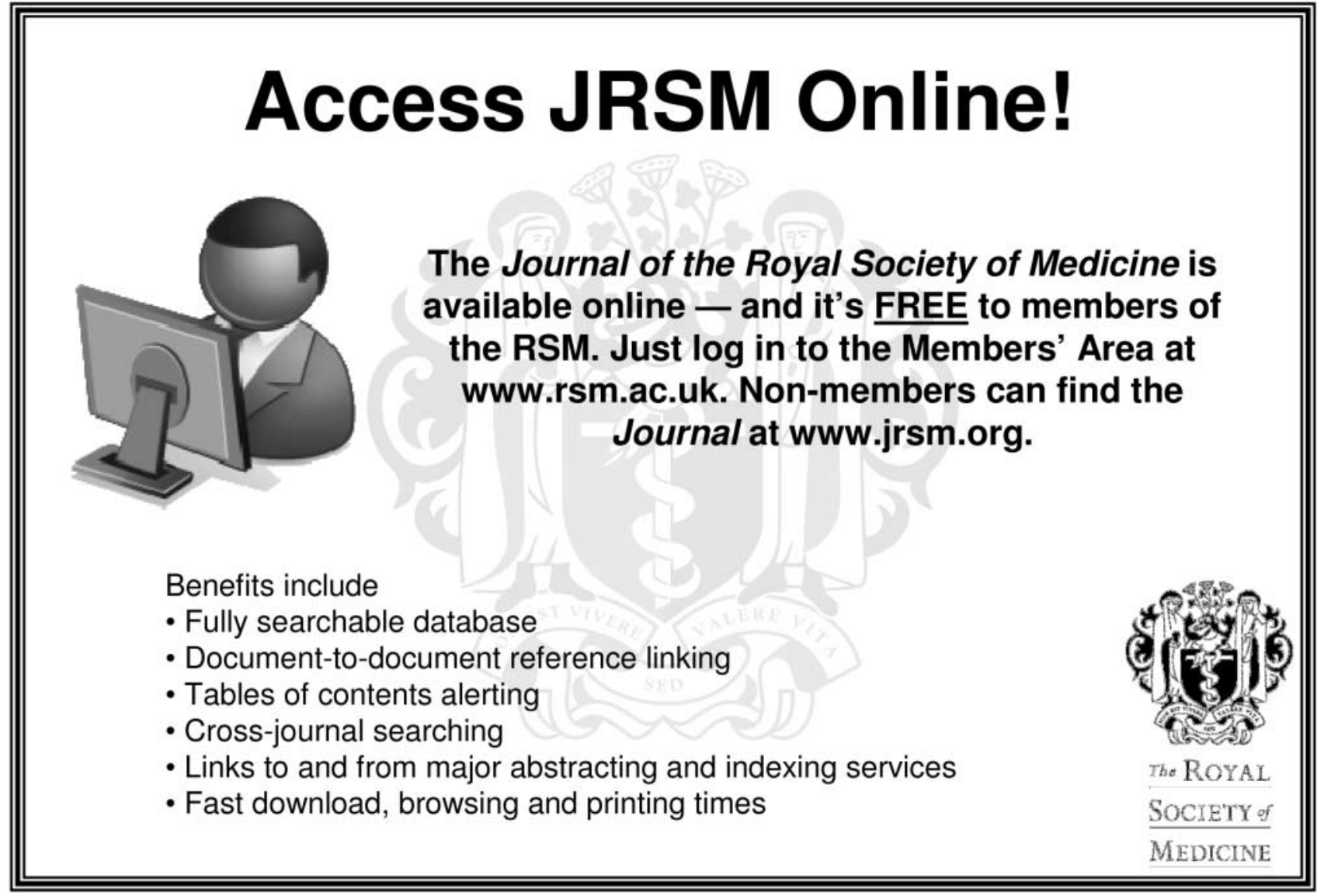

